we find hitherto an empty place, an element stands possessing an atomic and molecular weight of 0.4 , and he adds that this element might be identical with Young's "coronium." This part of the periodic arrangement is:-

$$
\begin{aligned}
& \text { Groups }
\end{aligned}
$$

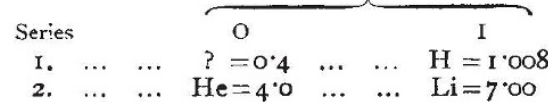

As there must be a definite ratio between the densities of the four gases $\mathrm{A}, \mathrm{B}, \mathrm{C}$, and $\mathrm{D}$ and their radius of rotation corresponding to their maximal molecular concentration, it is not impossible that from the data obtained by Wolf the density of the lightest gas, i.e. its molecular weight, which must be identical with its atomic weight, might be calculated. As regards the heaviest unknown gas, D, if this is not a gas of the helium-argon group we may be allowed to point out that the existence of a gas possessing a larger atomic weight than hydrogen and a smaller atomic, but a larger molecular, weight than helium is not absolutely excluded.

Bohemian University, Prague, February 27.

\section{Bohuslav Brauner.}

\section{On the $\alpha$ Rays from Radium $B$.}

A RECENT number of the Physikalische Zeitschrift (x., 46, 1909) contains an article, by Frederic A. Harvey, in which he states that radium $B$ gives out $\alpha$ particles, the ionisation range of which in air lies between $2.6 \mathrm{~mm}$, and $3.0 \mathrm{~mm}$. In investigating these short-range $\alpha$ particles he used a modification of the method employed by Bragg and Kleeman (Phil. Mag., x., 318, 1905), but on account of the limited range of the radiation he did not use a cone of rays.

Some time ago the writer (Phil. Mag., xi., 806, 1906) investigated the same subject by an entirely different method, and reached the conclusion that radium $B$ did not give out a particles with sufficient velocity to ionise the air. I have recently repeated Harvey's experiment, but have been unable to get any indication whatever of the presence of short-range $\alpha$ particles. In addition to this, I have employed a third method, which eliminated most of the difficulties inherent in the previous one.

The principle of the method is very simple, and involves no change in the position of the testing vessel or wire during the experiment; it is based on the fact that the range of the $\alpha$ particles is increased by reducing the pressure of the air. The two plates of my testing vessel were placed $5 \mathrm{~mm}$. apart; the lower one, which was of wire gauze, was $5 \mathrm{~mm}$. above the active wire. Now, if none of the $\alpha$ particles present had a range in air at atmospheric pressure of less than 1o $\mathrm{mm}$., then the ionisation current should vary as the pressure. If, however, radium $B$ gives out $\alpha$ particles having a range of about $2.5 \mathrm{~mm}$., and if they produce about the same number of ions per $\mathrm{cm}$. of path as the $\alpha$ particles from radium $\mathrm{C}$, then, after the pressure is reduced to half an atmosphere, the short-range $\alpha$ particles will begin to enter the testing vessel, and the ionisation will remain constant until the pressure has fallen to a quarter of an atmosphere. At this point the path of these $a$ particles will extend through the entire depth of the testing vessel, and as the pressure is still further decreased the ionisation will again become proportional to the pressure.

The results of this experiment have shown that - the ionisation in the testing vessel is approximately proportional to the pressure of the air from $76 \mathrm{~cm}$. to $3 \mathrm{~cm}$. It would, therefore, seem fair to conclude that there was not present on the active wire any substance giving out a particles which had a range in air from $1 \mathrm{~mm}$. to $5 \mathrm{~mm}$.

It should also be pointed out that Harvey's reason for attributing the short-range $\alpha$ particles to radium $B$ is at fault. He assumes that after I40 minutes radium $B$ has practically disappeared, and that only radium $\mathrm{C}$ remains. The theory of radio-active transformations, however, re- quires that, after 140 minutes, the number of atoms of radium $\mathrm{B}$ and radium $\mathrm{C}$ changing per second shall be very nearly the same. McGill University, Montreal, March 20. HOWARD L. BRONSON.

\section{British Association-Winnipeg Meeting.}

Ir is becoming more and more noticeable at the meetings of the association that communications are read which are of special interest to members of sections other than that to which each of the papers happens to be presented. In fact, there is little doubt that interests are now far too much subdivided at our meetings, and that one of the main purposes of the association is therefore unfulfilled. Many of us have felt the desirability of associating sections for the consideration of topics of common interest-not merely for set debates.

I am glad to say that the arrangement is being made that at Winnipeg Sections $\mathrm{A}$ and $\mathrm{B}$ shall sit together on the Friday; Sections B, K, and the Subsection of Agriculture on the Monday; Sections $B$ and $I$ on the Tuesday. Wheat is to be the main subject of consideration on the Monday, and food on the Tuesday. It is hoped that it will be possible to treat these two important topics somewhat fully, so as to present, in abstract form, a clear statement of our present state of knowledge, and thereby guide public opinion as well as influence inquiry.

Henry E. Armstrong.

\section{Fluorescence of Lignum Nephriticum.}

Musschenbroek, referred to by Mr. Shaxby in Nature of April I (p. 128), is evidently quoting from Boyle's memorable experiment, nearly a hundred years earlier. Mr. Shaxby will find it in the fifth volume of Boyle's works as follows:-

"If you make an infusion of Lignum Nephriticum in spring water it will appear of a deep colour like that of oranges when you place the vial between the window and your eye, and of a fine deep blue when you look on it with your eye placed between it and the window" ("Experimenta et Observationes Physica").

The history of the discovery is so fully dealt with in Tyndall's well-known lectures on light that it is surprising that anyone should imagine that Sir David Brewster was the first to observe fluorescence.

The Lignum Nephriticum is the Indian horse-radish tree, still cultivated for its fruit, which is eaten as a vegetable or pickled. The root has a flavour similar to that of horse-radish, and its title, nephriticum, is derived from the belief of the old pharmacologists that it was useful in cases of disease of the kidneys.

Charles E. Benham.

Essex County Standard Office, Colchester, April 3.

\section{The Ancestry of the Marsupialia.}

In the notice (NATure, December 24, I908) of Prof. A. A. W. Hubrecht's paper on the early ontogeny of the Mammalia, the writer states that the view adopted by Prof. Hubrecht, according to which the Metatheria are the descendants of placental ancestors, is in direct opposition to my own. May I be permitted to correct this statement, and to point out that it is just this view which I have all along advocated, and still hold? As a matter of fact, the idea that the Metatheria and Eutheria may best be regarded as the divergent branches of an ancestral placental stock was first definitely expressed in a joint paper by Prof. J. T. Wilson and myself (Quart. Journ. Micros. Sc., vol. xxxix., p. 579).

The Zoological Laboratory, University College, W.C., March 24.

I TAKE Prof. Hubrecht to mean that the Didelphia (Metatheria) are descended from Eutheria, which is what Prof. Hill, in his own letter, refuses to admit.

The Writer of the Note.

NO. 2058 , VOL. 80$]$ 